\title{
Healthcare Providers' Perceptions on the Timing of Initial Advance Care Planning Discussions in Japan: a Mixed-Methods Study
}

\author{
Jun Miyashita, $P h D^{1,2}$ (D) Ayako Kohno, $P h D^{3}$, Sayaka Shimizu, $P h D^{4,5}$, \\ Motohiro Kashiwazaki, MD 6 , Noriki Kamihiro, $M D^{6}$, Kaoru Okawa, MD', \\ Masami Fujisaki, $P h D^{8}$, Shunichi Fukuhara, DMSc ${ }^{1,4,9}$, and Yosuke Yamamoto, $P h D^{2}$
}

\begin{abstract}
'Department of General Medicine, Shirakawa Satellite for Teaching And Research (STAR), Fukushima Medical University, 2-1 Toyochikamiyajiro, Shirakawa, Fukushima, Japan; ${ }^{2}$ Department of Healthcare Epidemiology, School of Public Health in the Graduate School of Medicine, Kyoto University, Kyoto, Japan; ${ }^{3}$ Internationalization Promotion Office, School of Public Health in the Graduate School of Medicine, Kyoto University, Kyoto, Japan; ${ }^{4}$ Section of Clinical Epidemiology, Department of Community Medicine, Graduate School of Medicine, Kyoto University, Kyoto, Japan; Institute for Health Outcomes \& Process Evaluation Research (iHope International), Kyoto, Japan; ${ }^{6}$ The Kansai Centre for Family Medicine, Kanai Hospital, Kyoto, Japan; ${ }^{7}$ Department of Home Care Medicine, Kameda Medical Center, Chiba, Japan; ${ }^{8}$ Department of General Medicine, Medical Center Narita Hospital, Chiba, Japan; ${ }^{9}$ Center for Innovative Research for Communities and Clinical Excellence, Fukushima Medical University, Fukushima, Japan.
\end{abstract}

BACKGROUND: Most adult patients are willing to discuss advance care planning before the onset of any illness. There might be differences in preferences for timing when it comes to initiating advance care planning discussions by healthcare providers with patients.

OBJECTIVE: To identify healthcare providers' willingness to initiate advance care planning discussions in Japan.

DESIGN: A mixed-methods questionnaire comprising three case scenarios based on three different illness trajectories.

PARTICIPANTS: The study participants were physicians and nurses employed in four community hospitals in Japan.

MAIN MEASURES: Percentages of physicians' and nurses' willingness to initiate advance care planning discussions at four stages of patients' illness trajectory were quantitatively determined, and perceptions on preferred timing were qualitatively identified.

KEY RESULTS: From 108 physician and 123 nurse respondents (response rate: 99\%), 291 physician and 362 nurse responses about three case scenarios were obtained. Overall, $51.2 \%$ of physicians and $65.5 \%$ of nurses $(p<0.001)$ accepted discussion before illness. Less than one-third of physicians considered advance care planning a "wise precaution," while about two-thirds of nurses did. Additionally, more than half of both physicians and nurses preferred to postpone advance care planning until the patient's imminent death.

CONCLUSIONS: Physicians are less willing than nurses to begin advance care planning discussions before patients' health has deteriorated though most prefer to wait until the patients are close to death. Healthcare providers' attitudes toward advance care planning will need to be addressed to improve rates of completion in Japan.

Prior Presentations The 3rd Annual Meeting of the Society for Clinical Epidemioloau: September 29 ${ }^{\text {th }}$ 2019: Fukuoka Japan

Received August 4, 2020

Accepted December 20, 2020

Published online February 5, 2021
KEY WORDS: advance care planning; Japan; healthcare provider; mixedmethods study.

J Gen Intern Med 36(10):2935-42

DOI: $10.1007 / \mathrm{s} 11606-020-06524-4$

(C) Society of General Internal Medicine 2021

\section{INTRODUCTION}

Advance care planning (ACP) enables individuals to define goals and preferences for future medical treatment and care, to discuss these goals and preferences with family and healthcare providers, and to record and review these preferences, if appropriate. ${ }^{1}$ Discussions with family and/or with healthcare providers about ACP are vitally important in end-of-life care. However, it is difficult to determine factors which trigger discussions because chronic diseases are often not recognized as terminal even with advanced disease; if the condition suddenly changed, people would lose opportunities for discussions. ${ }^{2}$ There are several barriers faced by healthcare providers in their efforts to initiate discussions in primary care settings. ${ }^{3,4}$ For example, physicians expressed fear of diminishing patients' positive coping strategies by raising the topic of ACP too early. ${ }^{5}$ A nationwide survey in Japan reported that about half of the physicians working in palliative care units were not actively involved in the ACP process. ${ }^{6}$ However, the general population in Japan desires receiving information about end-of-life care from healthcare providers. ${ }^{7}$ More than $70 \%$ of patients in both Taiwan and Japan were willing to begin discussions while they were still healthy, and $90 \%$ in both countries were willing to start talking about ACP before suffering incapacitation. ${ }^{8}$ Thus, there is a gap between the perceptions of healthcare providers and patients about initiating discussions. There might also be a gap between different types of healthcare professionals, such as physicians 
and nurses. A previous study demonstrated that nurses felt more barriers to initiating ACP discussions than physicians. ${ }^{9}$

Identification of differences between the perceptions of patients and healthcare providers, and those between different healthcare professionals, could help reduce barriers to earlier ACP discussion initiation.

Our study aims to evaluate the willingness of physicians and nurses in Japan to initiate discussions at different stages of patients' physical decline.

\section{METHODS}

\section{Study Design and Setting}

We conducted a survey from September 2017 to March 2018 seeking understanding of patients' and healthcare providers' preferred timings for initial ACP discussion, using a convergent parallel mixed-methods design ${ }^{10}$ with three different scenarios in three questionnaires comprising multiple-choice and open-ended questions ${ }^{8}$ (Supplementary Figure 1: study procedure diagram). Study participants were healthcare providers employed in four participating hospitals (Shirakawa Kosei General Hospital in Shirakawa, Kanai Hospital in Kyoto, Kameda Medical Center in Kamogawa, and Medical Center Narita Hospital in Narita). The ethics committee of the Kyoto University Graduate School and Faculty of Medicine (R1029-1) approved this study.

\section{Participants}

In each hospital, all physicians belonging to the departments of cardiology, pulmonology, family medicine, general internal medicine, neurology, endocrinology, hematology, gastroenterology, and surgery were invited to participate in this survey. At least 30 medicine ward nurses, regardless of whether specialty certification, were randomly sampled from each hospital (sample target: 120 nurses). As they were likely to have experience with providing end-of-life care for older patients with various illness trajectories, those with less than 3 years of experience were excluded. Participants were informed that they were under no obligation to answer any questions and that they were able to rescind their consent to participate at any time. They were also informed that completing the questionnaire was regarded as consent to participate. After completing the questionnaire, participants received an honorarium worth approximately US\$20.

\section{Questionnaire Development}

About $85 \%$ of terminally ill adult patients follow one of the following three illness trajectories to reach the frail stage: ${ }^{11,12}$ prolonged deterioration, gradual decline punctuated by acute episodes, and rapid decline. We created three scenarios (cerebral infarction, heart failure, and incurable lung cancer) representing these three trajectories. The process of developing these scenarios and questionnaires has been previously described. ${ }^{8}$ Pilot testing on three physicians and five nurses established a final version of questionnaires. Figure 1 shows the trajectory of the illness through a prolonged deterioration (see Supplementary Figures 2 and 3 for the two other illness trajectories). All participants received the questionnaire including the three case scenarios. If they had experiences of caring for aged patients with either pneumonia, cerebral infarction, or dementia, they responded to the questions regarding case scenario 1 (cerebral infarction). If they had experiences of caring for those with heart failure, they responded to the questions regarding case scenario 2 (heart failure). If they had experiences of caring for those with cancer, they responded to the questions regarding case scenario 3 (incurable lung cancer; Supplementary text: case scenario question items in English-translated version).

\section{Outcome Variables}

We defined ACP discussions as "to make patients' wishes known to persons close to them about the kind of healthcare, including life-sustaining treatments, they wish to receive or not to receive if they should become very ill or injured."13-15 We defined four stages as possible acceptable timing for the initiation of discussions based on the five components of frailty: unintentional weight loss, self-reported exhaustion, slow walking speed, weakness, and low physical activity according to the study of Fried et al. ${ }^{16}$ We defined frailty stage 0 as having no component of frailty (i.e., healthy); frailty stage 1 as having only one component; frailty stage 2 as having two components; and frailty stage 3 as having three or more of the above five components (Supplementary Table 1). The explanation of ACP was provided at the beginning of every ques-

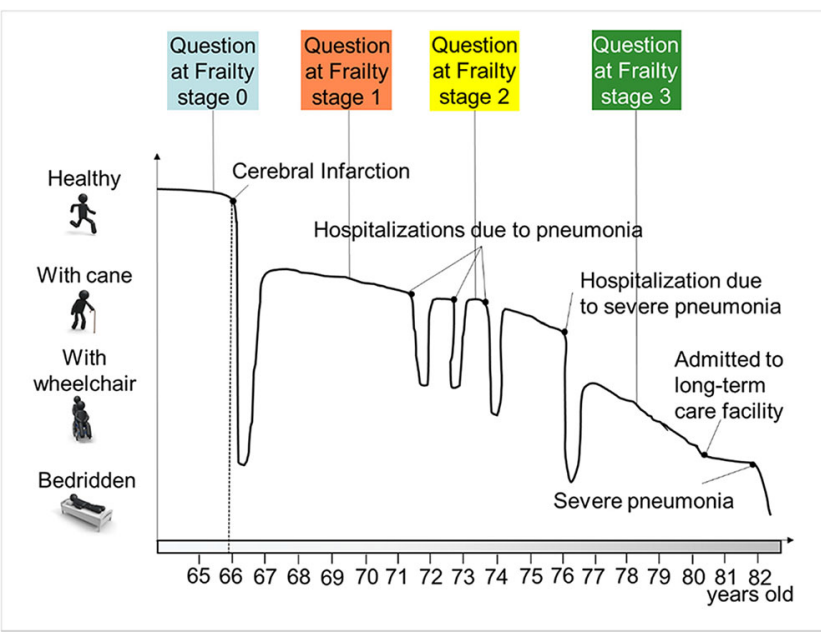

Figure 1 Illness trajectory of scenario 1 (cerebral infarction). Note. Adapted from Miyashita et al. (2020). Copyright 2020 by "SAGE Publishing." 
tionnaire which participants read before reading the scenario description. Participants read scenarios about patients at each frailty stage. After reading each scenario, participants were asked, "If you were the healthcare provider described here, what would you say about starting to discuss ACP with this patient at this time?" The answers on a five-point Likert scale were "It's too early," "It's slightly early," "It's an appropriate time," "It's a little late," and "It's too late." Those who selected the "too early" and "slightly early" answers were asked to proceed to the next frailty stage. Those who selected one of the three "appropriate" or "late" answers were asked to skip to the summary and outcome page. The stage at which participants selected either "appropriate" or "late" answers for the first time was defined as the time at which they were considered willing to discuss ACP with patients.

In addition, we elicited responses of healthcare provider attitudes by asking an open-ended question: "Describe how you would feel about beginning discussing ACP before you indicated (by choosing "appropriate," "a little late," or "too late") that you are willing to begin ACP with your patients."

\section{Data Analysis}

Quantitative Analyses. We described healthcare providers' data on how early participants were willing to initiate discussions with patients, using frequency analyses and descriptive summary statistics. Differences between the frailty stages selected by physicians and nurses were explored using the chi-squared test (Stata/IC v.15, College Station, TX, USA).

Qualitative Analyses. Responses to open-ended questions were analyzed using qualitative content analysis. ${ }^{17,18}$ We used this method to classify the transcribed answers into categories that represent similar meanings to clarify participants' perceptions underlying their selection of the frailty stage at which they were willing to initiate discussions. After reviewing codes from a previous study, ${ }^{8}$ three authors (JM, AK, MK) independently coded the 53 responses obtained from the participants in Shirakawa Kosei General Hospital to determine the initial codes. They discussed the coding labels and established a preliminary code list. The remaining 175 responses from those in the other three hospitals were equally divided among the three authors. When they found new codes, the three authors discussed them. The codes were classified into categories in accordance with the differences and similarities in codes Finally, the categories and quotations in Japanese were translated into English by the first author JM and bilingual author AK. Responses, codes, and categories were managed using NVivo 11 (QSR International).

Integration of Quantitative and Qualitative Analyses. We integrated quantitative and qualitative results using a joint display $^{10}$ (Fig. 4), which demonstrates underlying perceptions among participants selecting frailty stage 0 in all three scenarios.

\section{RESULTS}

A total of 231 healthcare providers (physicians: 108; nurses: 123) participated with a total of 693 responses (291 from physicians; 362 from nurses). The mean ages of physicians and nurses were similar ( $44 \pm 11$ years old). Nurses were more likely to be women $(95 \%)$ than physicians (15\%, Table 1$)$. The response rate was $99 \%$.

\section{Quantitative Results}

Nurses were more likely than physicians to select frailty stage $0(51.2 \%$ vs $65.5 \%, p<0.001)$ in overall scenarios. Either frailty stage 0 or frailty stage 1 was selected by $84 \%$ in physicians and $93 \%$ in nurses ( $p<0.001$, Fig. 2). Results for the three individual scenarios are almost similar to the overall results in terms of comparison between physicians and nurses. In the scenarios with a longer duration of illness trajectories, healthcare providers were less likely to select frailty stage 0 (Fig. 3).

\section{Qualitative Results}

In total, there were 101 codable physician and 122 nurse responses. Table 2 shows categories of perceptions underlying the stage at which respondents were willing to initiate discussions with patients. Four main categories were extracted.

Wise Precaution. Those who believed that ACP discussions are important in preparation for possible incapacitation in the future: Nurses more commonly expressed this belief (63\%) than physicians $(27 \%, p<0.001)$.

It is extremely important to engage in ACP as early as possible, even when patients are healthy. Some healthy patients might refuse discussions, thinking that it is too soon. In that case, we would not force them to discuss it. They can discuss it in another setting. However, it would be meaningful to provide all patients with a chance for discussion so that they are aware [of the importance of ACP]. (ID: 15023, 51-year-old female physician)

If patients had conveyed their opinions about end-oflife care in case of sudden changes in health condition, their family would be able to consent to their opinions and make decisions about their end-of-life care. That's why it is good to hold discussions at the early stage of their disease. (ID: 13008, 25-year-old female nurse) 
Table 1 Participants' Demographics

\begin{tabular}{|c|c|c|c|c|}
\hline \multirow{2}{*}{$\begin{array}{l}\text { Participant } \\
\text { demographics }\end{array}$} & \multicolumn{2}{|c|}{ Physician } & \multicolumn{2}{|l|}{ Nurse } \\
\hline & $N=108$ & $\begin{array}{l}\text { Missing } \\
\text { data }\end{array}$ & $N=123$ & $\begin{array}{l}\text { Missing } \\
\text { data }\end{array}$ \\
\hline $\begin{array}{l}\text { Age, mean, range } \\
\text { (SD) }\end{array}$ & $\begin{array}{l}44,28- \\
75 \\
(11.5)\end{array}$ & 0 & $\begin{array}{l}44,24 \\
65 \\
(11.4)\end{array}$ & 0 \\
\hline Women, number $(\%)$ & $\begin{array}{l}15 \\
(13.9)\end{array}$ & 0 & $\begin{array}{l}119 \\
(96.8)\end{array}$ & 0 \\
\hline $\begin{array}{l}\text { Experience of } \\
\text { profession, number } \\
(\%)\end{array}$ & & 10 & & 0 \\
\hline $\begin{array}{l}\geq 3 \text { years, }<10 \\
\text { years } \\
\geq 10 \text { years, }<20 \\
\text { years } \\
\geq 20 \text { years }\end{array}$ & $\begin{array}{l}34 \\
(34.7) \\
31 \\
(31.6) \\
33 \\
(33.7)\end{array}$ & & $\begin{array}{l}32 \\
(26.0) \\
40 \\
(32.5) \\
51 \\
(41.5)\end{array}$ & \\
\hline $\begin{array}{l}\text { Experience of ACP } \\
\text { discussion, number } \\
(\%)\end{array}$ & & 14 & & 0 \\
\hline $0-9$ & $\begin{array}{l}17 \\
(18.1)\end{array}$ & & $\begin{array}{l}56 \\
(45.5)\end{array}$ & \\
\hline $10-19$ & $\begin{array}{l}20 \\
(21.3)\end{array}$ & & $\begin{array}{l}43 \\
(35.0)\end{array}$ & \\
\hline 20 or more & $\begin{array}{l}57 \\
(60.6)\end{array}$ & & $\begin{array}{l}24 \\
(19.5)\end{array}$ & \\
\hline $\begin{array}{l}\text { Preference for end- } \\
\text { of-life care,* number } \\
(\%)\end{array}$ & & 0 & & 1 \\
\hline Do not want LSTs & $\begin{array}{l}96 \\
(88.9)\end{array}$ & & $\begin{array}{l}111 \\
(91.0)\end{array}$ & \\
\hline Want LSTs & $1(0.9)$ & & $0(0)$ & \\
\hline $\begin{array}{l}\text { Entrust decision- } \\
\text { making to family }\end{array}$ & $5(4.6)$ & & $4(3.3)$ & \\
\hline $\begin{array}{l}\text { Do not know own } \\
\text { preference }\end{array}$ & $6(5.6)$ & & $7(5.7)$ & \\
\hline $\begin{array}{l}\text { Responses of case } \\
\text { scenarios, number } \\
(\%)\end{array}$ & & 0 & & 0 \\
\hline Cerebral infarction & $\begin{array}{l}102 \\
(94.4)\end{array}$ & & $\begin{array}{l}123 \\
(100)\end{array}$ & \\
\hline Heart failure & $\begin{array}{l}90 \\
(83.3)\end{array}$ & & $\begin{array}{l}116 \\
(94.3)\end{array}$ & \\
\hline $\begin{array}{l}\text { Incurable lung } \\
\text { cancer }\end{array}$ & $\begin{array}{l}99 \\
(91.7)\end{array}$ & & $\begin{array}{l}123 \\
(100)\end{array}$ & \\
\hline $\begin{array}{l}\text { Total responses of } \\
\text { case scenarios }\end{array}$ & 291 & & 362 & \\
\hline
\end{tabular}

$A C P$, advance care planning; $L S T$, life-sustaining treatments

*The question to participants: "Please think about situations in which you might become seriously ill or injured, or severely demented, and unable to express your own wishes when the possibility of recovering is very low. In that sort of situation, would you want to receive lifesustaining treatment(s)?" Participants selected an answer from the following alternatives: "I do not want LSTs," "I would want LSTS, " "I would entrust these decisions to my family," or "I do not know my own preference(s)"

Postponement of ACP Until Patients' Imminent End-ofLife. Physicians and nurses had similar responses (55\% vs. $54 \%, p=0.84)$.

Most Japanese are either not feeling comfortable about having a clear image about their own death, or they often avoid thinking about death, so we (healthcare providers) cannot have constructive discussions about ACP with patients when they are not at the end-of-life stage. (ID: 15027, 47-year-old male physician)

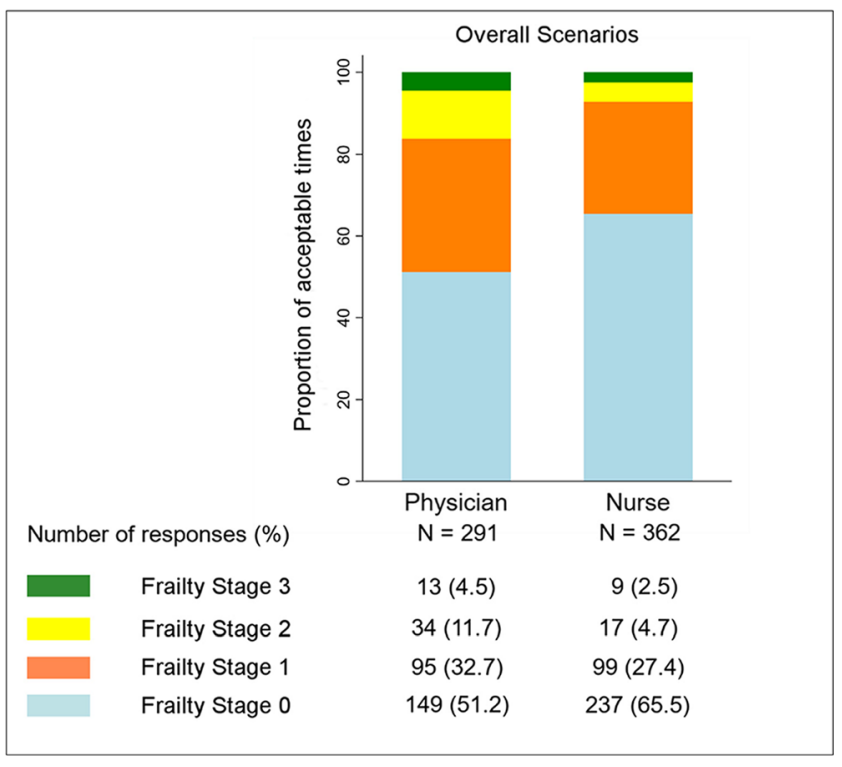

Figure 2 Percentages of acceptable times for initiating advance care planning discussions among physicians and nurses.

If we start to discuss ACP with patients when they are healthy, they do not realize their future situation, thinking, "Why are they talking about this? I am very healthy!" In addition, they would feel uneasy, thinking, "Am I in such a bad health condition? Is my future so bleak?” (ID: 16062, 32-year-old female nurse)

\section{ACP Discussions at Healthcare Providers' Initiative.} Physicians (18\%) and nurses (24\%) had similar rates of belief that healthcare providers should take the lead in initiating discussions.

If we guide discussions of ACP, taking time to make sure patients understand what we are talking about, that kind of discussion would be very useful even for middle-aged patients. (ID: 13036, 29-year-old male physician)

Discussions about ACP between patients and their family members are very important but sometimes difficult to initiate. Therefore, it would be easier for patients to initiate discussions when healthcare providers broach the topic as a third party. (ID: 16070, 38-year-old female nurse).

Timing Depends on Patients' Needs. The fourth category posits that patients' values, characteristics, and mental conditions, but not the stage of illness, determine the timing of initiating discussions. In addition, there were some descriptions in this category about developing a trusting relationship between healthcare providers and patients which 


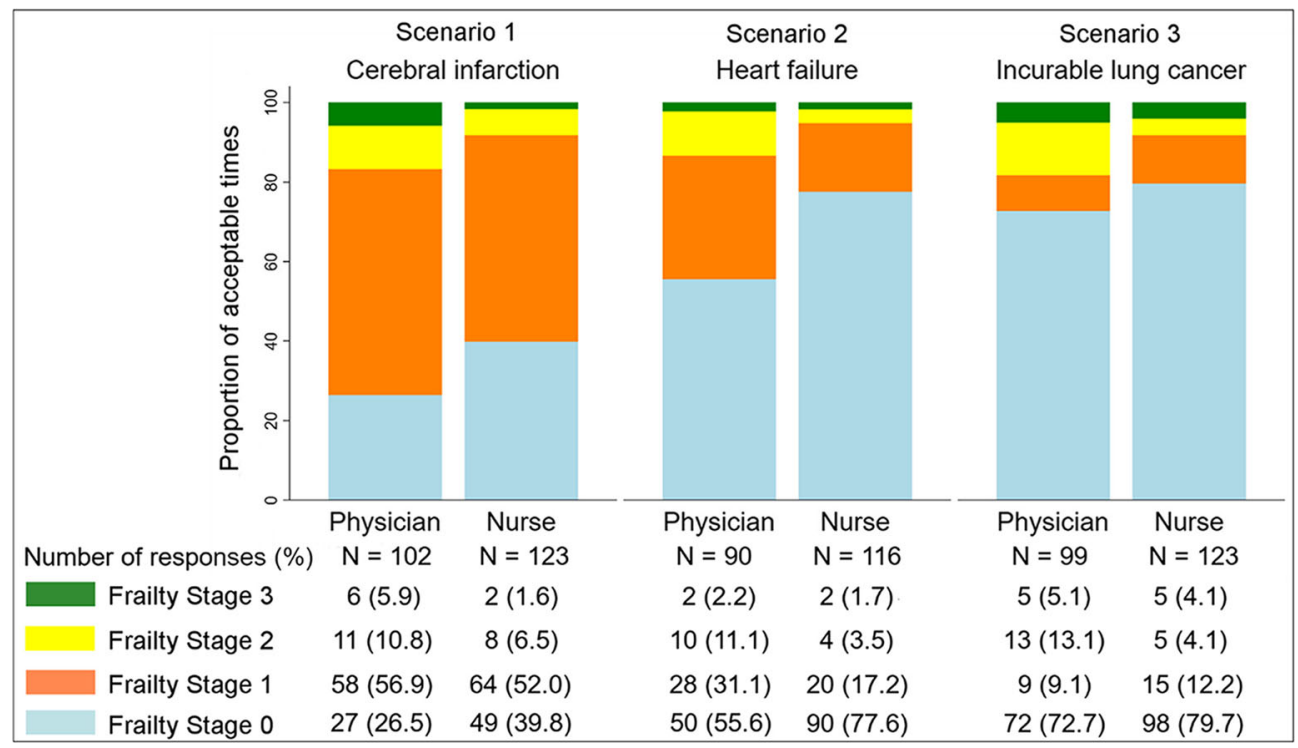

Figure 3 Percentages of acceptable times for initiating advance care planning discussions by scenario among physicians and nurses.

is important for initiating discussions. Physicians $(25 \%)$ and nurses $(18 \%)$ had similar rates of belief in this category.

Whether meaningful discussions can be held or not depends on patients' needs. If patients want to discuss ACP, I don't feel the distress in initiating the discussions. If patients do not wish [to discuss care planning], then I feel distressed to discuss at physician's own initiative. (ID: 16135, 41-year-old male physician)

If there is a good trusting relationship between patients and healthcare providers, then we, nurses, can discuss $\mathrm{ACP}$ with patients and their families at the early stage of their onset of diseases. Before developing such a relationship, patients might feel uncomfortable when

Table 2 Categories of Patients' Responses to Open-Ended Questions About Their Motives for Choosing the Most Acceptable Time for Initiating ACP Discussions

\begin{tabular}{|c|c|c|c|}
\hline \multirow{2}{*}{$\begin{array}{l}\text { Four main categories and } \\
\text { other minor categories }\end{array}$} & \multicolumn{2}{|l|}{ No. $(\%)^{*}$} & \multirow{2}{*}{$\begin{array}{l}p \\
\text { value } \dagger\end{array}$} \\
\hline & $\begin{array}{l}\text { Physician, } \\
n=101\end{array}$ & $\begin{array}{l}\text { Nurse, } \\
n=122\end{array}$ & \\
\hline 1. Wise precaution & 27 (27) & $77(63)$ & $<0.001$ \\
\hline $\begin{array}{l}\text { 2. Postponement of ACP } \\
\text { until patients' imminent end- } \\
\text { of-life }\end{array}$ & $56(55)$ & $66(54)$ & 0.84 \\
\hline $\begin{array}{l}\text { 3. ACP discussions at } \\
\text { healthcare providers' } \\
\text { initiative }\end{array}$ & $18(18)$ & $29(24)$ & 0.28 \\
\hline $\begin{array}{l}\text { 4. Timing depends on } \\
\text { patients' needs }\end{array}$ & $25(25)$ & $22(18)$ & 0.22 \\
\hline $\begin{array}{l}\text { Other minor categories } \\
\text { Discussions about patients' } \\
\text { end-of-life are stressful }\end{array}$ & $6(6)$ & $6(5)$ & \\
\hline Too busy to discuss ACP & $4(4)$ & $0(0)$ & \\
\hline
\end{tabular}

$A C P$, advance care planning

*The category percentages add up to more than $100 \%$ because respondents' descriptions fall into multiple categories

the $p$ values in each main category for differences in percentages between physicians and nurses were obtained using the chi-squared test we start to discuss it, and we feel anxious about how to broach the topic. (ID: 13015, 59-year-old female nurse).

In other minor categories, a few physicians and no nurses stated that they were too busy to discuss ACP with their patients at healthy stages. In other low-frequency categories, a few physicians and nurses stated that they felt stressed by talking about end-of-life care with patients.

\section{Integration of Quantitative and Qualitative Results}

Figure 4 shows the integrated results. The right side of Fig. 4 represents the percentages of those who selected frailty stage 0 in all three scenarios among the four categories. Most responses (122) were in the second category, "postponement of $A C P$," but the percentage of responses of those preferring

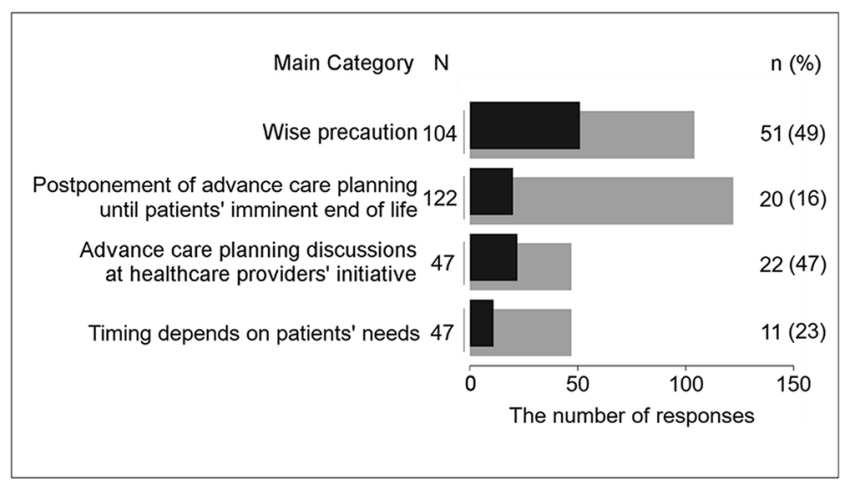

Figure 4 Percentages of healthcare providers preferring frailty stage 0 (while healthy) for initiation of advance care planning by the main category of motive for selection. Note. $N$ (the height of the grey bar) represents the total number of healthcare providers in each main category; $n$ (the height of the black bar) represents the number of healthcare providers selecting frailty stage 0 in all scenarios in each main category; the number in parentheses represents the percentage of healthcare providers selecting frailty stage 0 in all scenarios in each main category. 
frailty stage 0 in the second category was the lowest (16\%). Half of those describing the first category, "wise precaution," selected frailty stage 0 in all three scenarios.

\section{DISCUSSION}

Japanese physicians were less willing than nurses to initiate ACP discussions when patients were healthy, both overall and in the three individual scenarios. The qualitative results showed that only $27 \%$ of physicians stated that ACP is a wise precaution, while over $60 \%$ of nurses stated the same. These qualitative results complemented the quantitative results because those describing "wise precaution" tended to select frailty stage 0 for the initiation of discussions.

Both physicians and nurses showed a low likelihood of selecting frailty stage 0 for initiating ACP discussions in scenarios with longer illness trajectories and diseases other than cancer. These findings might be explained by those of several previous studies indicating that healthcare providers consider it more difficult to find key moments to discuss ACP with patients who have conditions other than cancer, such as heart failure and dementia, ${ }^{19}$ and to engage in $\mathrm{ACP}$ with patients with dementia as compared to those without dementia. $^{20}$

We previously did a similar study among Japanese patients, ${ }^{8}$ used the same scenarios and found that more than $70 \%$ of Japanese patients were willing to initiate discussions while they are healthy and around $90 \%$ of them are willing to initiate when they are at frailty stage 0 or frailty stage 1 . This was true for all three scenarios. In contrast, we found that a much lower percentage of physicians selected frailty stage 0 in all three scenarios than patients.

From the qualitative results, the percentage of the patients who mentioned that ACP was a wise precaution was $66 \%$ of the patients in the previous study. Nurses had similar beliefs $(63 \%)$, while only $27 \%$ of the physicians in this current study held similar views. These qualitative results complemented the quantitative results of the selection of frailty stage 0 , because respondents who answered "wise precaution" tended to select frailty stage 0 for the initiation of ACP discussions in both studies compared with those answering other categories. From these results, it was found that there were gaps between patients and healthcare providers, especially between patients and physicians. Physicians tend to select later stages of frailty for initiating discussions than patients do.

In addition, the qualitative results of our study showed that over $50 \%$ of physicians chose "postponement of ACP until patients' imminent end-of-life," which means that discussions could not be initiated until patients felt end-of-life as imminent. This is because they felt uncomfortable when discussions were started too early. The integrated result of this study reveals that healthcare providers who chose "postponement of ACP until patients' imminent end-of-life" tended to select later frailty stages for initiating discussions (Fig. 4). Our results are consistent with those of previous studies reporting that physicians feared patients' negative reactions when they initiate ACP too early, worrying that patients may not be able to maintain hope ${ }^{5}$ and that ACP may harm healthcare provider-patient relationships. ${ }^{19,21}$

In the process of $\mathrm{ACP}$, the healthcare provider-patient relationship could be affected by cultural features specific to Japan, which contribute to the way of thinking about end-oflife and death. In a previous study, Japanese adults considered "unawareness of impending death" and "leaving the decision to a medical expert" as components of a good death. ${ }^{22}$ In this context, healthcare providers are sometimes concerned that discussions about end-of-life care might undermine patients' experience of a good death. ${ }^{23}$ As a result, healthcare providers have little involvement in $\mathrm{ACP},{ }^{24}$ which is a barrier to healthcare provider-patient interactions regarding ACP. ${ }^{25}$ However, it is also true that Japanese adults with good family relationships sometimes discuss ACP with their kin from the same generation, such as spouses, siblings, and siblings' spouses. They discuss to reach a consensus about their preferences for end-of-life cares so that their children can make final decisions without feeling a sense of burden. ${ }^{24,26}$ On the contrary, Japanese older adults who do not have good family relationships may refrain from expressing their preferences for end-of-life care. ${ }^{24,26,27}$ Healthcare providers should play a mediating role in the process of ACP to deal with discordance between older adults' desires regarding end-of-life care and what they feel compelled to do for the sake of family members. ${ }^{24,28}$

The finding that Japanese nurses were more willing than physicians to initiate ACP discussions when patients were healthy was surprising because a previous study from Canada $^{9}$ reported that nurses felt more barriers to initiating discussions than physicians. Japan tends to prioritize interdependence rather than autonomy in medical ethics. ${ }^{29-31}$ The cultural values of caregiving are mainly centered on a sense of empathy in the Japanese society. ${ }^{32,33}$ This sense of empathy, "Omoiyari," is defined as the ability and willingness to feel what others are feeling. ${ }^{29}$ Through this, Japanese nurses anticipate and accommodate the needs of patients. ${ }^{34}$ Therefore, Japanese nurses might infer patients' needs of initiating discussions when they are still healthy because most patients think that ACP is a wise precaution. This might be a possible explanation for the finding that Japanese nurses were more willing than physicians to initiate discussions when patients were healthy.

Our study has several limitations. First, because it is scenario-based, it is uncertain whether the findings accurately reflect healthcare providers' actual behavior. Second, our results may not be generalizable to other countries because cultural and societal factors might influence healthcare providers' preferences for end-of-life care discussions. Third, because we did not perform back translation of transcripts and categories in qualitative analyses from Japanese to 
English, the adequacy of the translation might have been compromised, although the second author, AK, truly bilingual in English and Japanese, was involved in the translation process.

We identified that there was discordance between physicians' and nurses' willingness to discuss ACP. It is important to deal with the discordance between physicians' and patients' preferred timing of initial ACP to promote timely discussions. Our findings might hopefully initiate the facilitation of physicians' attempts to surmount hurdles to timely discussions.

Corresponding Author: Jun Miyashita, PhD; Department of General Medicine, Shirakawa Satellite for Teaching And Research (STAR), Fukushima Medical University, 2-1 Toyochikamiyajiro, Shirakawa, Fukushima 961-0005, Japan (e-mail: jun-miya@umin.ac.jp).

Supplementary Information The online version contains supplementary material available at https://doi.org/10.1007/s11606-020 06524-4.

Author Contributions Miyashita had full access to all the data collected in the study and takes responsibility for the integrity of the data and the accuracy of the data analysis.

Study concept and design: Miyashita, Kohno, Shimizu, Fukuhara, and Yamamoto

Collection of data: Miyashita, Kamihiro, Okawa, and Fujisaki

Analysis and interpretation of data: Miyashita, Kohno, Shimizu,

Kashiwazaki, and Yamamoto

Drafting of the manuscript: Miyashita

Critical revision of the manuscript for important intellectual content: Miyashita, Kohno, Shimizu, Kashiwazaki, Kamihiro, Okawa, Fujisaki, Fukuhara, and Yamamoto

Funding This work was supported by an international joint research grant from the Pfizer Health Research Foundation 2016-2017 (principal investigator: Miyashita).

\section{Compliance with Ethical Standards:}

Conflict of Interest: The authors declare that they do not have a conflict of interest.

\section{REFERENCES}

1. Rietjens JAC, Sudore RL, Connolly M, et al. Definition and recom mendations for advance care planning: an international consensus supported by the European Association for Palliative Care. Lancet Oncol. 2017;18(9):e543-e51.

2. Mullick A, Martin J, Sallnow L. An introduction to advance care planning in practice. BMJ (Clinical research ed). 2013;347:f6064.

3. Gott M, Gardiner C, Small N, et al. Barriers to advance care planning in chronic obstructive pulmonary disease. Palliat Med. 2009;23(7):642-8.

4. Munday D, Petrova M, Dale J. Exploring preferences for place of death with terminally ill patients: qualitative study of experiences of general practitioners and community nurses in England. BMJ (Clinical research ed). 2009;339:b2391.
5. Boyd $\mathbf{K}$, Mason B, Kendall M, et al. Advance care planning for cancer patients in primary care: a feasibility study. Br J Gen Pract. 2010;60(581):e449-58.

6. Nakazawa $\mathbf{K}$, Kizawa $\mathbf{Y}$, Maeno $\mathbf{T}$, et al. Palliative care physicians practices and attitudes regarding advance care planning in palliative care units in Japan: a nationwide survey. The American journal of hospice \& palliative care. 2014;31(7):699-709.

7. Ministry of Health Labour and Welfare. The attitude survey for end-of-life care, Summary of the report. 2017. Available at: https://www.mhlw.go. jp/toukei/list/dl/saisyuiryo_a_h29.pdf. Accessed 23 Nov 2018.

8. Miyashita J, Kohno A, Cheng SY, et al. Patients' preferences and factors influencing initial advance care planning discussions' timing: a cross-cultural mixed-methods study. Palliat Med. 2020;34(7):906-16

9. You JJ, Downar J, Fowler RA, et al. Barriers to goals of care discussions with seriously ill hospitalized patients and their families: a multicenter survey of clinicians. JAMA Intern Med. 2015;175(4):549-56.

10. Creswell JW. A concise introduction to mixed methods research. Thousand Oaks: Sage Publication; 2015.

11. Murray SA, Kendall M, Boyd K, Sheikh A. Illness trajectories and palliative care. BMJ (Clinical research ed). 2005;330(7498):1007-11.

12. Lynn J. Living long in fragile health: the new demographics shape end of life care. The Hastings Center Report. 2005;35(6):S14-S8.

13. Boerner K, Carr D, Moorman S. Family relationships and advance care planning: do supportive and critical relations encourage or hinder planning? J Gerontol B Psychol Sci Soc Sci. 2013;68(2):246-56.

14. Carr D, Moorman SM, Boerner K. End-of-life planning in a family context: does relationship quality affect whether (and with whom) older adults plan? J Gerontol B Psychol Sci Soc Sci. 2013;68(4):586-92.

15. Teixeira AA, Hanvey L, Tayler C, et al. What do Canadians think of advanced care planning? Findings from an online opinion poll. BMJ Support Palliat Care. 2015;5(1):40-7.

16. Fried LP, Tangen CM, Walston J, et al. Frailty in older adults: evidence for a phenotype. J Gerontol A Biol Sci Med Sci. 2001;56(3):M146-56.

17. Morgan DL. Qualitative content analysis: a guide to paths not taken. Qual Health Res. 1993;3(1):112-21.

18. Hsieh HF, Shannon SE. Three approaches to qualitative content analysis. Qual Health Res. 2005; 15(9):1277-88.

19. De Vleminck A, Pardon K, Beernaert $\mathbf{K}$, et al. Barriers to advance care planning in cancer, heart failure and dementia patients: a focus group study on general practitioners' views and experiences. PLoS One. 2014;9(1):e84905.

20. Meeussen K, Van den Block L, Echteld M, et al. Older people dying with dementia: a nationwide study. Int Psychogeriatr. 2012;24(10):1581-91.

21. Pfeifer MP, Sidorov JE, Smith AC, Boero JF, Evans AT, Settle MB. The discussion of end-of-life medical care by primary care patients and physicians: a multicenter study using structured qualitative interviews. The EOL Study Group. Journal of general internal medicine. 1994;9(2):82-8.

22. Miyashita M, Morita T, Sato K, Hirai K, Shima Y, Uchitomi Y. Good death inventory: a measure for evaluating good death from the bereaved family member's perspective. Journal of pain and symptom management. 2008;35(5):486-98.

23. Sanjo M, Miyashita M, Morita T, et al. Preferences regarding end-of-life cancer care and associations with good-death concepts: a populationbased survey in Japan. Ann Oncol. 2007;18(9):1539-47.

24. Miyashita J, Kohno A, Yamamoto Y, et al. How psychosocial factors contribute to japanese older adults' initiation of advance care planning discussions: a qualitative study. J Appl Gerontol. 2020:733464820911537.

25. Aoki T, Miyashita J, Yamamoto Y, et al. Patient experience of primary care and advance care planning: a multicentre cross-sectional study in Japan. Family practice. 2017;34(2):206-12.

26. Miyashita J, Yamamoto Y, Shimizu S, et al. Association between socia networks and discussions regarding advance care planning among Japanese older adults. PLoS One. 2019;14(3):e0213894.

27. Shimada $\mathbf{C}$, Nkazato $\mathbf{K}$, Arai $\mathbf{K}$, et al. Communication with important others regarding their preferences for end-of-life care. Nihon Ronen Igakkai Zasshi. 2015;52(1):79-85.

28. Bito S, Matsumura S, Singer MK, Meredith LS, Fukuhara S, Wenger NS. Acculturation and end-of-life decision making: comparison of 
Japanese and Japanese-American focus groups. Bioethics. 2007;21(5):251-62.

29. Lebra TS. Japanese patterns of behavior. Honolulu, Hawaii 96822: University of Hawaii Press; 1976.

30. Elwyn TS, Fetters MD, Gorenflo W, Tsuda T. Cancer disclosure in Japan: historical comparisons, current practices. Soc Sci Med. 1998;46(9):1151-63.

31. Voltz R, Akabayashi A, Reese C, Ohi G, Sass HM. End-of-life decisions and advance directives in palliative care: a cross-cultural survey of patients and health-care professionals. Journal of pain and symptom management. 1998;16(3):153-62.

32. Asai MO, Kameoka VA. The influence of sekentei on family caregiving and underutilization of social services among Japanese caregivers. Social Work. 2005;50(2): 111-8.

33. Yamaguchi S, Cohen SR, Uza M. Family caregiving in Japan: the influence of cultural constructs in the care of adults with cancer. Journal of Family Nursing. 2016;22(3):392-418.

Publisher's Note Springer Nature remains neutral with regard to jurisdictional claims in published maps and institutional affiliations. 